\title{
Investigational Product Supply Plan
}

National Cancer Institute

\section{Source}

National Cancer Institute. Investigational Product Supply Plan. NCI Thesaurus. Code C115760.

A proposed method to describe the supply management of an investigational product (IP), including the details regarding to quantity of active, placebo, comparator, and/or rescue supplies needed to fulfill the requirements of a clinical study protocol over the course of a clinical trial. 